\title{
Diagnostic Value of Dermoscopic Findings of Hair and Scalp in Cicatricial Alopecia
}

Keywords: Cicatricial alopecia; Dermoscopy; Hair and scalp Abstract

Background: Cicatricial Alopecias are a group of uncommon hair loss disorders, which are characterized by permanent destruction of hair follicles. Dermoscopy is a recent enlightening tool in the dermatological diagnostic field.

Objective: To evaluate the dermoscopic findings of Cicatricia Alopecia and the possibility of utilizing dermoscopy for assessment of Cicatricial Alopecia

Patients and Methods: Thirty patients with Cicatricial Alopecia were the subjects of this study. They were classified according to the clinicopathological diagnosis into: Discoid lupus erythematosus 10 cases $(33.3 \%)$, lichen planopilaris 3 cases $(10 \%)$, folliculitis decalvans 2 cases $(6.7 \%)$, pseudopelade of brocq 2 cases $(6.7 \%)$, acne keloidalis 3 cases $(10 \%)$ and finally other secondary causes 10 cases $(33.3 \%)$. The skin lesions were examined histopathologically to confirm the diagnosi and the lesions were examined dermoscopically.

Results: The dermoscopic diagnosis of the patients proved the following diagnoses: Discoid lupus erythematosus 8 cases $(26.7 \%)$ lichen planopilaris 3 cases $(10 \%)$, acne keloidalis 3 cases $(10 \%)$, folliculitis decalvans 2 cases (6.7\%), undiagnosed 4 cases (13.3\%), other secondary causes 10 cases (33.3\%) and no cases diagnosed as pseudopelade of broca

Conclusion: The dermoscope provides a practical and useful aid for the clinical diagnosis of different types of Cicatricial Alopecia.

\section{Introduction}

Scalp alopecias are considered a broad spectrum of heterogeneous diseases and they are among the most common dermatologic disorders [1]. Alopecias are classified into non-cicatricial and cicatricial forms. Pathologically, the scar is the end point of reparative fibrosis with permanent destruction of preexisting tissue [2].

Cicatricial Alopecias (CA) are a group of uncommon inflammatory hair loss disorders, which are characterized by permanent destruction of hair follicles. Clinically there is loss of visible follicular ostia in scarring area, with or without epidermal atrophy and histologically there is absence of pilosebaceous structures which are replaced by fibrous tract [3]. Cicatricial Alopecia may be divided into a 'primary' condition when the follicle is the main target of the disease process or a 'secondary' event when the follicle acts as an 'innocent bystander' in the course of a disease occurring outside the follicular unit [4].

Primary Cicatricial Alopecias (PCAs) are probably the most misdiagnosed scalp disorders and frequently cause major distress for the affected patient. These scalp diseases represent trichologic emergencies because hair follicles are permanently destroyed and therefore the patient might experience disfiguration, psychological embarrassment, and lack of self-esteem. A quick and confident proof of diagnosis and aggressive treatment in the case of active disease are

\section{Journal of}

Clinical \& Investigative Dermatology

\author{
Kandil AH ${ }^{1}$, Abdelshafy $\mathrm{AS}^{1^{*}}$ and El-Kashishi KA ${ }^{2}$ \\ ${ }^{\prime}$ Department of Dermatology and Venereology, Zagazig University, Egypt \\ ${ }^{2}$ Department of Pathology, Zagazig University, Egypt
}

\section{*Address for Correspondence}

Abdelshafy AS, Department of Dermatology and Venereology, Zagazig University, Zagazig, Egypt, Tel: 201008364064; Email: ahmed_said3007@yahoo.com

Submission: 29 September, 2018

Accepted: 5 November, 2018

Published: 6 November, 2018

Copyright: (c) 2018 Kandil AH, et al. This is an open access article distributed under the Creative Commons Attribution License, which permits unrestricted use, distribution, and reproduction in any medium, provided the original work is properly cited.

crucial in the management of PCA [5].

In 2001, the North American Hair Research Society (NAHRS) put forward a "proposed working classification of the primary Cicatricial Alopecias" based on the predominant type of inflammatory cell component [6]. Four groups have been considered as follows: lymphocytic, neutrophilic, mixed, and non-specific. Lymphocytic CAs include Chronic Cutaneous Lupus Erythematosus (CCLE), Lichen Planopilaris (LPP), Pseudopelade of Brocq (PPB), central Centrifugal Cicatricial Alopecia (CCCA), Alopecia Mucinosa (AM), Keratosis Follicular is Spinulosa Decalvans (KFSD). Neutrophilic CAs includes Folliculitis Decalvans (FD) and Dissecting Cellulitis (DC). Mixed CAs includes Acne Keloidalis Nuchae (AKN) and acne necroticavarioliformis.

Trichoscopy is dermoscopy of the hair and scalp. This is a noninvasive, in office technique that can be performed with a handheld dermoscope or a digital videodermoscopy system. Trichoscopy helps for magnified observation of four components|: (1) hair shafts, (2) hair follicle openings, (3) the perifollicular epidermis, and (4) blood vessels. Abnormalities in the appearance of these 4 structural components of the scalp aid in the differential diagnosis of hair loss [7]

The aim of the study was to evaluate the dermoscopic findings of Cicatricial Alopecia and the possibility of utilizing dermoscopy for assessment of Cicatricial Alopecia.

\section{Patients and Methods}

\section{Patients}

This study included thirty patients with different clinical varieties of CA. The patients were selected from the Outpatient Clinic of Dermatology and Venereology Department, Zagazig University Hospitals, during the period from January 2015 to August 2015 after obtaining the approval of the research ethics committee of the hospital (code no. ZUIRB\#1743-14-12-0-2-14) and written informed consent from each participant.

The inclusion criteria include patients with hair loss, diagnosed 
Citation: Kandil AH, Abdelshafy AS, El-Kashishi KA. Diagnostic Value of Dermoscopic Findings of Hair and Scalp in Cicatricial Alopecia. J Clin Investigat Dermatol. 2018;6(2): 5

ISSN: 2373-1044

Table 1: Checklist of dermoscopic features.

\begin{tabular}{|c|c|c|}
\hline Blood Vessel & $\begin{array}{c}\text { Perifollicular and } \\
\text { Interfollicular } \\
\text { Skin Surface }\end{array}$ & Hair Follicle Openings: Dots \\
\hline $\begin{array}{c}\text { White and milky red } \\
\text { homogenous area } \\
\text { Dark brown scattered } \\
\text { vessels } \\
\text { thick arborizing } \\
\text { vessels }\end{array}$ & $\begin{array}{c}\text { Bluish deep discoloration } \\
\text { Perifollicular scaling } \\
\text { Tubular scaling } \\
\text { Folds of epidermal } \\
\text { hyperplasia }\end{array}$ & $\begin{array}{c}\text { Yellow dot with radial thin } \\
\text { arborizing vessels }\end{array}$ \\
& $\begin{array}{c}\text { Pin point white dots } \\
\text { Fibrotic white dots }\end{array}$ \\
& Follicular red dots \\
& Tufts of hair \\
\hline
\end{tabular}

Table 2: Clinicopathological diagnoses of the studied group.

\begin{tabular}{|c|c|c|}
\hline Clinicopathological diagnosis & \multicolumn{2}{|c|}{ (n=30) } \\
\cline { 2 - 3 } & No. & $\%$ \\
\hline Discoid Lupus Erythematosus (DLE) & 10 & 33.3 \\
\hline Lichen planopilaris (LPP) & 3 & 10 \\
\hline Folliculitis decalvan (FD) & 2 & 6.7 \\
\hline Pseudopelade of brocq (PPB) & 2 & 6.7 \\
\hline Acne keloidalis (AK) & 3 & 10 \\
\hline Secondary cicatricial alopecia & 10 & 33.3 \\
\hline
\end{tabular}

Table 3: Dermoscopic diagnoses of the studied group.

\begin{tabular}{|c|c|c|}
\hline \multirow{2}{*}{ Dermoscopic diagnosis } & \multicolumn{2}{|c|}{$(\mathbf{n = 3 0}$} \\
\cline { 2 - 3 } & No. & $\%$ \\
\hline Discoid Lupus Erythematosus (DLE) & 8 & 26.7 \\
\hline Lichen planopilaris (LPP) & 3 & 10 \\
\hline Folliculitis decalvans (FD) & 2 & 6.7 \\
\hline Pseudopelade of brocq (PPB) & 0 & 0 \\
\hline Acne keloidalis (AK) & 3 & 10 \\
\hline Secondary cicatricial alopecia & 10 & 33.3 \\
\hline undiagnosed & 4 & 13.3 \\
\hline
\end{tabular}

clinically as Cicatricial Alopecia established by histopathological examination at any age, sex, and duration. Those with any hair and scalp disorders other than Cicatricial Alopecia like alopecia are ata, seborrheic dermatitis, psoriasis and acute telogen effluvium were excluded from the study.

\section{Methods}

All Subjects in this study were subjected to complete history taking including personal history, family history of a similar condition, present history including onset, course, duration and previous therapy as well as past history of drug intake or systemic disease. General examination was done to diagnose any systemic disease. Dermatological examination was done including site, size, and texture of the skin and distribution of hair loss.

\section{Histopathological examination}

Four mm punch biopsy specimens were obtained from each patient from the edge of the lesion. The specimens were fixed in $10 \%$ neutral buffered formalin and processed for paraffin embedding. 4 $\mu \mathrm{m}$ sections was obtained from paraffin blocks and stained with Haematoxylin and Eosin (Hx.\&E.) stain for histopathological diagnosis.

\section{Dermscopic examination}

The dermoscope used: Dermlite II PRO HR (3Gen, USA). Derm
Lite II model, palm-sized, large $25 \mathrm{~mm}$ lens permits scalp visualization at a 10-fold magnification, without an interface solution. The digital camera used is (Sony Cyber-shot DSC-W710) (Sony corp, Tokyo, Japan), which offers high resolution (16, 1 megapixel) that produced imagery with a magnification of 50-fold via its 5 -fold optical zoom lens, which helped us in magnifying the lesion viewed by the dermoscope. It has a large screen (2.7 inch LCD) and rechargeable lithium-ion battery. Photos were obtained by the digital camera. Several different
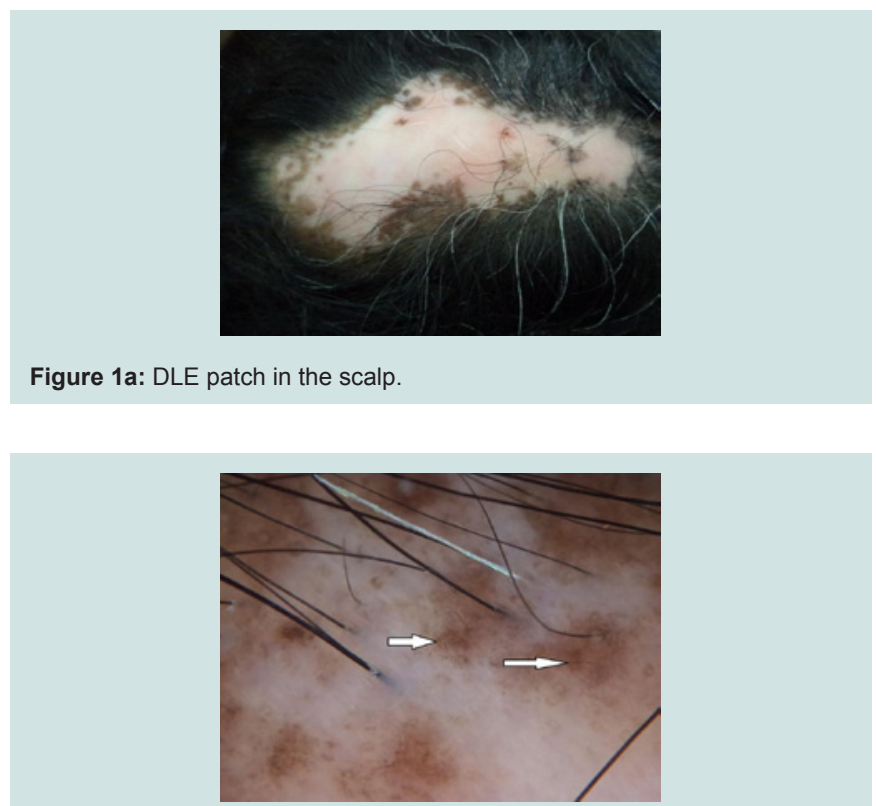

Figure 1b: Yellow dots containing thin spider vessels (arrows) in inactive discoid lupus erythematosus.

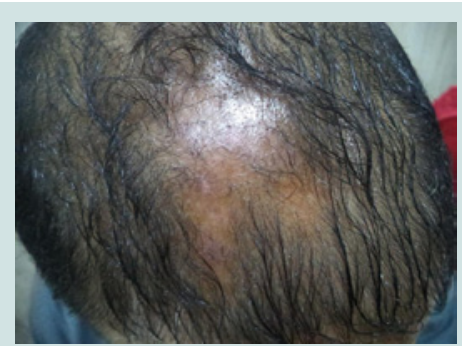

Figure 2a: LPP in the scalp.

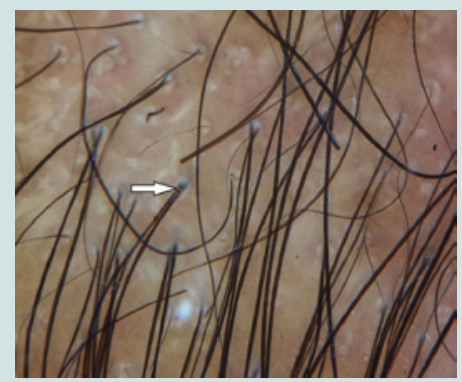

Figure 2b: Perifollicular collar scaling in lichen planopilaris by dermoscopy Scales form silver-white tubular structures around the emerging hair shafts usually reaching about $1-3 \mathrm{~mm}$ above the scalp surface (arrow). 
Citation: Kandil AH, Abdelshafy AS, El-Kashishi KA. Diagnostic Value of Dermoscopic Findings of Hair and Scalp in Cicatricial Alopecia. J Clin Investigat Dermatol. 2018;6(2): 5

ISSN: 2373-1044

Table 4: Relation between dermoscopic findings and diagnosis of the studied group.

\begin{tabular}{|c|c|c|c|c|c|c|c|c|}
\hline & $\begin{array}{c}\text { DLE } \\
n=10 \\
(33.3 \%)\end{array}$ & $\begin{array}{c}\text { LPP } \\
n=3 \\
(10 \%)\end{array}$ & $\begin{array}{c}F D \\
n=2 \\
(6.66)\end{array}$ & $\begin{array}{c}\text { PPB } \\
n=2 \\
(6.66)\end{array}$ & $\begin{array}{c}\text { AK } \\
n=3 \\
(10 \%)\end{array}$ & $\begin{array}{c}2 r y \\
n=10 \\
(33.3 \%)\end{array}$ & $x^{2}$ & $\mathbf{P}$ \\
\hline -Thick arborizing vessels & 3 & 0 & 0 & 0 & 0 & 0 & 6.66 & 0.25 \\
\hline $\begin{array}{l}\text {-White \& milky red } \\
\text { homogenous area }\end{array}$ & 4 & 0 & 1 & 0 & 1 & 9 & 11.81 & $0.04^{*}$ \\
\hline $\begin{array}{l}\text {-Dark brown scattered } \\
\text { discoloration }\end{array}$ & 5 & 0 & 0 & 0 & 0 & 0 & 12 & $0.04^{*}$ \\
\hline -Bluish deep discoloration & 0 & 3 & 0 & 1 & 0 & 0 & 30 & $<0.001^{*}$ \\
\hline -Perifollicular scaling & 7 & 0 & 2 & 0 & 3 & 2 & 13.2 & $0.02^{*}$ \\
\hline -Tubular scaling & 0 & 0 & 0 & 0 & 0 & 1 & 2.07 & 0.84 \\
\hline - large yellow dots & 8 & 0 & 0 & 0 & 0 & 0 & 21.82 & $0.001^{*}$ \\
\hline -Folds of epidermal hyperplasia & 0 & 0 & 1 & 0 & 0 & 0 & 14.48 & $0.01^{\star}$ \\
\hline - large White dots & 0 & 3 & 2 & 2 & 1 & 1 & 22.54 & $<0.001^{*}$ \\
\hline -Follicular red dots & 4 & 0 & 0 & 0 & 0 & 0 & 9.23 & 0.10 \\
\hline -Tufts of hair & 0 & 0 & 2 & 0 & 3 & 0 & 30 & $<0.001^{*}$ \\
\hline -Yellow follicular pustule & 0 & 0 & 2 & 0 & 3 & 0 & 30 & $<0.001^{*}$ \\
\hline
\end{tabular}

images at 10- to50-fold magnifications were taken, and evaluated in accordance with the checklist of dermoscopic features presented in (Table 1).

\section{Statistical analysis}

All data obtained were analyzed with SPSS version 15 (IBM Co., New York, New York, USA). Data were summarized using mean \pm SD. Comparison of quantitative data was made using Student's $\mathrm{t}$-test. Comparison between groups was made using the $\mathrm{X}^{2}$-test and Fisher's exact test for qualitative variables. Statistical significance was determined at a level of $\mathrm{P}$ less than or equal to 0.05 .The sensitivity of a clinical test refers to the ability of the test to correctly identify those patients with the disease.

$$
\text { Sensitivity }=\frac{\text { True positives }}{\text { True positives }+ \text { False negatives }}
$$

\section{Results}

The studied patients were 13 males and 17 females with their ages ranging from 1 to55 years with a mean of $34.5 \pm 9.32$ years. The cases were 20 diagnosed as primary Cicatricial Alopecia and 10 diagnosed as secondary Cicatricial Alopecia. Secondary cases of Cicatricial Alopecia were 6 cases due to burns, 2 cases due to morphea and 2 cases due to trauma.

The clinicopathological diagnoses of the studied group were summarized in and in photos $1 \mathrm{a}, 2 \mathrm{a}, 3 \mathrm{a}, 4 \mathrm{a}$ and the dermoscopic diagnoses of the studied group were summarized in and in photos $1 b, 2 b, 3 b$ and $4 b$ (Table 2 and 3 ). The relation between dermoscopic findings and diagnosis of the studied group was summarized in (Table 4).

There was no significant difference between clinicopathological and dermoscopic diagnosis of the studied cases with $p$ value of 0.74 and the sensitivity of dermoscope in diagnosis of Cicatricial Alopecia in comparison to clinicopathological diagnosis was $86.7 \%$ (Table 5).

\section{Dermoscopic features in discoid lupus erythematosus}

Large yellow dots, dark brown scattered discoloration, thick arborizing vessels, yellow dot with radial thin arborizing vessels, and follicular red dots were detected only in DLE. Large yellow dots and dark brown scattered discoloration were significantly more common in DLE $(\mathrm{p}<0.001) \&(\mathrm{p}=0.04)$ respectively (Figure $1 \mathrm{a}$ and $1 \mathrm{~b})$.

Large yellow dots were reported in 8patients (80\%), dark brown scattered discoloration were reported in 5 patients (50\%), yellow dot with radial thin arborizing vessels were reported in 4 patients (40\%), follicular red dots were detected in 4 patients $(40 \%)$, and thick arborizing vessels were reported in 3 patients (30\%).

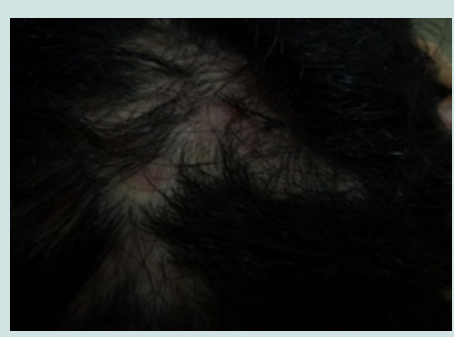

Figure 3a: Folliculitis decalvans in the scalp.

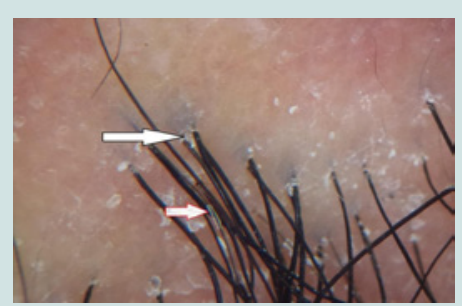

Figure 3b: The white arrow points to tubular scaling around three hairs emerging from a follicular unit. The red outlined arrow points to hair casts in folliculitis decalvans. 


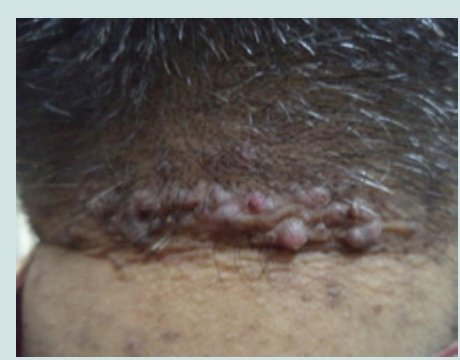

Figure 4a: Acne keloidalisnuchae.

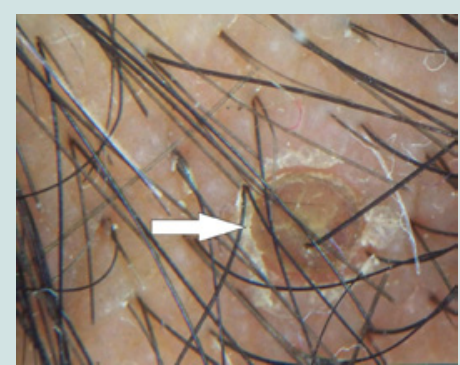

Figure 4b: Follicular pustules in acne keloidalis by dermoscopy (arrow)

Table 5: Validity of dermoscope in diagnosis in comparison to histopathology as a gold standard for diagnosis.

\begin{tabular}{|c|c|c|c|}
\hline \multirow{2}{*}{ Dermoscopic diagnosis } & \multicolumn{2}{|c|}{ Clinicopathological diagnoses } & \multirow{2}{*}{ Total } \\
\cline { 2 - 3 } & $+\mathrm{ve}$ & $-\mathrm{ve}$ & \\
\hline +ve & 26 & 0 & 26 \\
\hline -ve & 4 & 0 & 4 \\
\hline Total & 30 & 0 & 30 \\
\hline Sensitivity & \multicolumn{3}{|c}{} \\
\hline Accuracy & \multicolumn{3}{|c}{$86.7 \%$} \\
\hline
\end{tabular}

were reported in 50\%. Tufts of hair and yellow follicular pustule were detected in all cases of FD (100\%). They were significantly common in $\mathrm{FD}(\mathrm{p}<0.001)$ (Figure 3a and $3 \mathrm{~b})$.

\section{Dermoscopic features in acne keloidalis}

Tufts of hair and yellow follicular pustule were detected in all patients of AK. They were significantly more common in AK $(\mathrm{p}<0.001)$ (Figure $4 \mathrm{a}$ and $4 \mathrm{~b})$.

\section{Discussion}

Our study revealed the following characteristic dermoscopic features: In DLE, large yellow dots, dark brown scattered discoloration follicular red dots and thick arborizing vessels. Large yellow dots were seen in $80 \%$ of DLE patients and this finding was also detected by in $55 \%$ of patients, and in $70 \%$ of DLE patients by which are near to our study results [8,9]. Large yellow dots seen in DLE significantly differed from yellow dots observed in alopecia areata and androgenetic alopecia as they were larger and darker (dark-yellow to yellowbrown in color). Large yellow dots with radial, thin arborizing vessels emerging from the dot were found to be specific to DLE (Red spider in yellow dot) as it isn't seen in other causes of CA.
Scattered dark-brown discoloration of the skin giving a "dirty" appearance was observed in active DLE, in 50\% of DLE patients. This finding comes also in parallel to who reported it in $45 \%$ of DLE patients and was detected in 70\% DLE patients by $[8,9]$.

Thick arborizing vessels were found only in 30\% of DLE patients of our study. This proportion of thick arborizing vessels seen in our DLE lesions is much lower than that found by who found thick arborizing vessels in almost all patients with DLE [8]. However, thick arborizing blood vessels were seen in $80 \%$ cases of DLE patients by [9].This difference indicates that this finding isn't an absolute criterion for diagnosis of DLE dermoscopically and may be attributed to different patient selection with different activity of the disease. Thick arborizing vessels observed in DLE appeared slightly more irregular with variable thickness in the course of a vessel which differ from those found in BCC.

Follicular red dots were found in $40 \%$ of DLE patients. This much higher than that found by who detected it in only $5 \%$ of DLE patients and by who did not find it at all found follicular red dots in active DLE and their presence correlates with dilated infundibulum surrounded by dilated vessels with pronounced red blood cell extravasation [8-10]. The presence of follicular red dots in DLE lesions is a good prognostic feature and indicates high probability of hair regrowth.

In lichen planopilaris, the most characteristic dermoscopic features are: bluish deep discoloration and large white dots. We found bluish deep discoloration in all patients with LPP this finding was detected by in only $45 \%$ of patients [8]. This difference may be explained by long duration of LPP patients in our study. Our study confirms the presence of white dots in all patients with LPP and matches with the study of [11]. The classic white dots of LPP, which correspond to vertically-oriented fibrotic tracts in histopathology, may be observed in most primary Cicatricial Alopecias. They are irregular in shape, have blunt borders, and a tendency to merge and form white areas devoted of follicular opening and differ from the smaller "pinpoint" white dots, first observed in patients with dark skin and correspond to empty hair follicle openings or eccrine sweat duct openings. These "pin point" white dots are small, regularly oval, or circular shaped, sharply demarcated from the brown surrounding skin [12]. We did not find tubular perifollicular scaling, and elongated, parallel-oriented blood vessels. This may be due to end stage disease of our patients.

Dermoscopic features of pseudopelade of Brocq in our study are nonspecific including no features of inflammation and no perifollicular scaling and absent follicular openings and the skin colour is usually porcelain white. Thus, pseudopelade of Brocq is a diagnosis of exclusion both clinically and trichoscopically and this matches with the conclusion of [9]. In folliculitis decalvans, our study revealed the following characteristic rich scopic features: yellow and large follicular pustule with an emerging hair shaft, perifollicular scaling, tuft of hair, and folds of epidermal hyperplasia. Large follicular pustule with an emerging hair shaft is a hallmark of FD present in all patients. This finding was also detected in other studies as found black dots, absent follicular openings, elongated linear blood vessels, perifollicular erythema, epidermal atrophy and cicatricial white patches and no large follicular pustule with an emerging hair shaft $[8,9]$. Hair tufts surrounded by starburst pattern epidermal 
Citation: Kandil AH, Abdelshafy AS, El-Kashishi KA. Diagnostic Value of Dermoscopic Findings of Hair and Scalp in Cicatricial Alopecia. J Clin Investigat Dermatol. 2018;6(2): 5

hyperplasia described by found in all cases of FD corresponds in histopathology to hyperkeratosis, with parakeratosis overlying a hyperplastic epidermis [8]

White and milky-red areas lacking follicular openings were seen in all types of PCA. This finding was detected in most of the studies of PCA. Finally, our study revealed that there is no significant difference between histopathologic diagnosis and dermoscopic diagnosis.

\section{Conclusion}

The polarized-light handheld dermoscope attached to a digital camera provides a practical and useful aid for the clinical diagnosis of different types of Cicatricial Alopecia. Moreover, it has low cost and less invasiveness when compared to the histopathology.

We recommend further studies with larger number of patients and different stages of the disease activity.

\section{References}

1. KaradağKöse Ö, Güleç AT (2012) Clinical evaluation of alopecias using a handheld dermatoscope. J Am Acad Dermatol 67: 206-214.

2. Sellheyer K, Bergfeld WF (2006) Histopathologic evaluation of alopecias. Am J Dermatopathol 28: 236-259.

3. Abraham LS, Piñeiro-Maceira J, Duque-Estrada B, Barcaui CB, Sodré CT, e al. (2010) Pinpoint white dots in the scalp: dermoscopic and histopathologic correlation. J Am Acad Dermatol 63: 721-722.
4. Griffin LL, Michaelides C, Griffiths CE, Paus R, Harries MJ, et al. (2012) Primary cicatricial alopecias: a U.K. survey. Br J Dermatol 167: 694-697.

5. Mubki T, Rudnicka L, Olszewska M, Shapiro J (2014) Evaluation and diagnosis of the hair loss patient: part II. Trichoscopic and laboratory evaluations. J Am Acad Dermatol 71: e1-e11.

6. Otberg N (2013) Primary cicatricial alopecias. Dermatol Clin 31: 155-166

7. Olsen EA, Bergfeld WF, Cotsarelis G, Price VH, Shapiro J, et al. (2003) Workshop on Cicatricial Alopecia. Summary of North American Hair Research Society (NAHRS)-sponsored workshop on cicatricial alopecia, Duke University Medical Center, February 10 and 11, 2001. J Am Acad Dermatol 48: 103-110.

8. Mubki T, Rudnicka L, Olszewska M, Shapiro J (2014) Evaluation and diagnosis of the hair loss patient: part II. Trichoscopic and laboratory evaluations. J Am Acad Dermatol 71: e1-e11.

9. Rakowska A, Slowinska M, Kowalska-Oledzka E, Warszawik O, Czuwara J, et al. (2012) Trichoscopy of cicatricial alopecia. J Drugs Dermatol 11: 753758.

10. Thakur BK, Verma S, Raphael V (2015) Clinical, trichoscopic, and histopathological features of primary cicatricial alopecias: A retrospective observational study at a tertiary care centre of North East India. Int J Trichology 7: 107-112.

11. Tosti A, Torres F, Misciali C, Vincenzi C, Starace M, et al. (2009) Follicular red dots: a novel dermoscopic pattern observed in scalp discoid lupus erythematosus. Arch Dermatol 145: 1406-1409.

12. Ross EK, Tan E, Shapiro J (2005) Update on primary cicatricial alopecias. J Am Acad Dermatol 53: 1-37. 